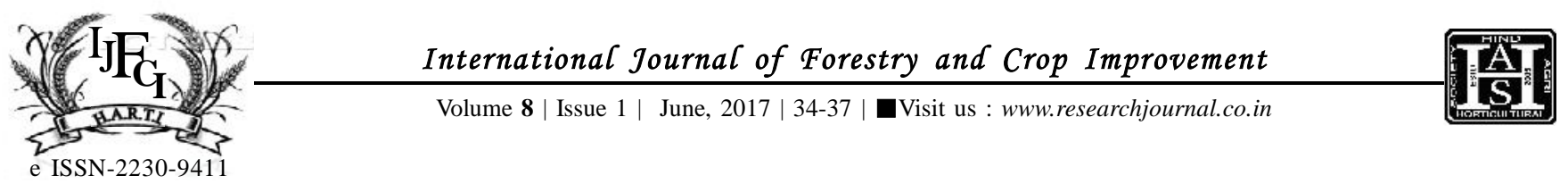

\title{
Diversity for branching habit in the natural population of walnut (Juglans regia L.) in the Kashmir valley
}

\author{
IMTIYAZ AHMADLONE
}

\begin{abstract}
The present investigation entitled diversity for growth habit in the natural population of walnut (Juglans regia L.) in the Kashmir valley was carried out in order to document the available genetic variability in walnut germplasm and to select elite walnut genotypes possessing superior attributes and quality traits. During the survey, data was recorded on one hundred fifty two (152) walnut trees growing in different areas of Kashmir valley. Remarkable variability was observed in seedling walnut trees for different morphological, nut and kernel characters. Similarly, variations were also reported for other characters viz., tree vigour, growth habit, branching habit, leaflet shape, shoot colour, nut shape, shell texture, shell colour, shell seal, shell strength, shell integrity, kernel shrivel and kernel colour. Studies on .branching habit revealed substantial variability among the seedling raised walnuts genotypes in Kashmir valley. In this study it was found that 30 genotypes (19.73\%) possessed sparse branching habit, 57 genotypes (37.50\%) exhibited intermediate branching habit and 65 genotypes $(42.77 \%)$ had dense branching habit.
\end{abstract}

KEY WORDS : Walnut, Diversity branching habit

HOW TO CITE THIS ARTICLE : Lone, Imtiyaz Ahmad (2017).Diversity for branching habit in the natural population of walnut (Juglans regia L.) in the Kashmir valley. Internat. J. Forestry \& Crop Improv., 8 (1) : 34-37, DOI: 10.15740/HAS/IJFCI/8.1/34-37.

ArTiCle ChronicaL : Received : 12.04.2017; Revised : 02.05.2017; Accepted : 14.05.2017

ADDRESS FOR CORRESPONDENCE

IMTIYAZ AHMAD LONE, Regional Research Station (SKUAST-K), Wadura, SOPORE (J\&K) INDIA 